\title{
Kupffer Cell Structure in the Juvenile Nile Crocodile, Crocodylus niloticus
}

\author{
Erna van Wilpe* and Hermanus Bernardus Groenewald \\ Department of Anatomy and Physiology, Faculty of Veterinary Science, University of Pretoria, \\ Private Bag X04, Onderstepoort 0110, Republic of South Africa
}

\begin{abstract}
The morphology of Kupffer cells was examined in the liver of the juvenile Nile crocodile using light microscopy and transmission electron microscopy. Pleomorphic Kupffer cells were located in the sinusoids, in the space of Disse, in the hepatic parenchyma and often connected adjacent sinusoids. The cell surfaces were irregular due to the presence of filopodia and lamelliapodia with phagocytosis of white blood cells, red blood cells and thrombocytes being evident. The cells were in close contact with endothelial cells and pit cells in the sinusoidal lumen and with stellate cells in the space of Disse. The cytoplasm contained large phagosomes comprising a combination of ceroid pigment, melanosomes and siderosomes. The nuclei were often indented and eccentrically placed due to the presence of the phagosomes. Conspicuous clusters of membrane-bound tubular organelles with a filamentous or crystalline interior were observed in the cytoplasm. The clusters were sometimes separated into smaller groups around phagosomes. A clear zone existed between the limiting membrane and the interior of these tubular organelles with the electron-dense interior profiles being, respectively, circular, angular or divided. The tubular organelles have not previously been described in Kupffer cells and possibly represent lysosomes with specialized functions. Mitochondria, microtubules, Golgi profiles, granular and smooth endoplasmic reticulum, and a few cytoplasmic lipid droplets were also present. The presence of the tubular organelles and the occurrence of the Kupffer cells in different locations in the liver of the juvenile Nile crocodile are indicative of particularly active and mobile cells.
\end{abstract}

KEY WORDS: Nile crocodile; Crocodylus niloticus; Kupffer cells; morphology; light microscopy; transmission electron microscopy

\section{INTRODUCTION}

Kupffer cells, also called stellate sinusoidal macrophages, are derived from monocytes and reside in liver sinusoids where they form part of the reticuloendothelial system (Ross et al., 2003). Kupffer cells represent a distinct cell population with unique differentiation mechanisms, metabolic functions and responsiveness to inflammatory agents (Naito et al., 2004). They play a pivotal role in host defence by eliminating toxic and foreign substances, removing degenerated red and white blood cells from the blood circulation and degrading hemoglobin to form hemosiderin and bilirubin (McCuskey and McCuskey, 1990; Dini et al., 2002; Ross et al., 2003; Naito et al., 2004; Fried, 2008; Smith and Laurie, 2010).

Although some studies have been done on the livers of nonmammalian vertebrates (Schaffner, 1998; McClellan-Green et al., 2006; Jacobson, 2007), there is a lack of information regarding the fine structural morphology of Kupffer cells. Literature describing this important component of the liver in crocodiles is limited to the West African crocodile (Storch et al., 1989), with information on the Kupffer cells of the Nile crocodile being nonexistent. The purpose of this study was to describe the light microscopical and ultrastructural features of Kupffer cells in the juvenile Nile crocodile, Crocodylus niloticus.

\section{MATERIALS AND METHODS}

Liver samples were obtained from five 1-year old Nile crocodiles C. niloticus Laurenti, 1768, that were donated to the Faculty of Veterinary Science, University of Pretoria, by Izintaba Crocodile Farm near Brits, North West Province, South Africa. They were euthanized by injecting sodium pentobarbital into the supravertebral vein and after muscular relaxation lateral incision lines were made on the left and right body wall to remove the skin, the ventral body wall and the ribs in order to expose the internal organs. Perfusion fixation was chosen as the method of fixation as the structural relationship in the liver is obscured by congestion when it is immersion-fixed. The portal vein to the right lobe was tied off in situ, the liver removed from the body cavity and connected to a peristaltic pump (H.R. Flow Inducer, Watson Marlow Limited, England). The liver was perfused with a $0.5 \%$ heparin sodium $(5000 \mathrm{IU} / \mathrm{ml})$ saline solution, using the pump at $80 \mathrm{ml} / \mathrm{min}$, to remove the blood from the sinusoids. The heparin solution was replaced with $2.5 \%$ glutaraldehyde in Millonig's phosphate buffer ( $\mathrm{pH} 7.4,0.13 \mathrm{M}$ ) and

*Correspondence to: Erna van Wilpe; Department of Anatomy and Physiology, Faculty of Veterinary Science, University of Pretoria, Private Bag X04, Onderstepoort 0110, Republic of South Africa. Email: erna.vanwilpe@up.ac.za 

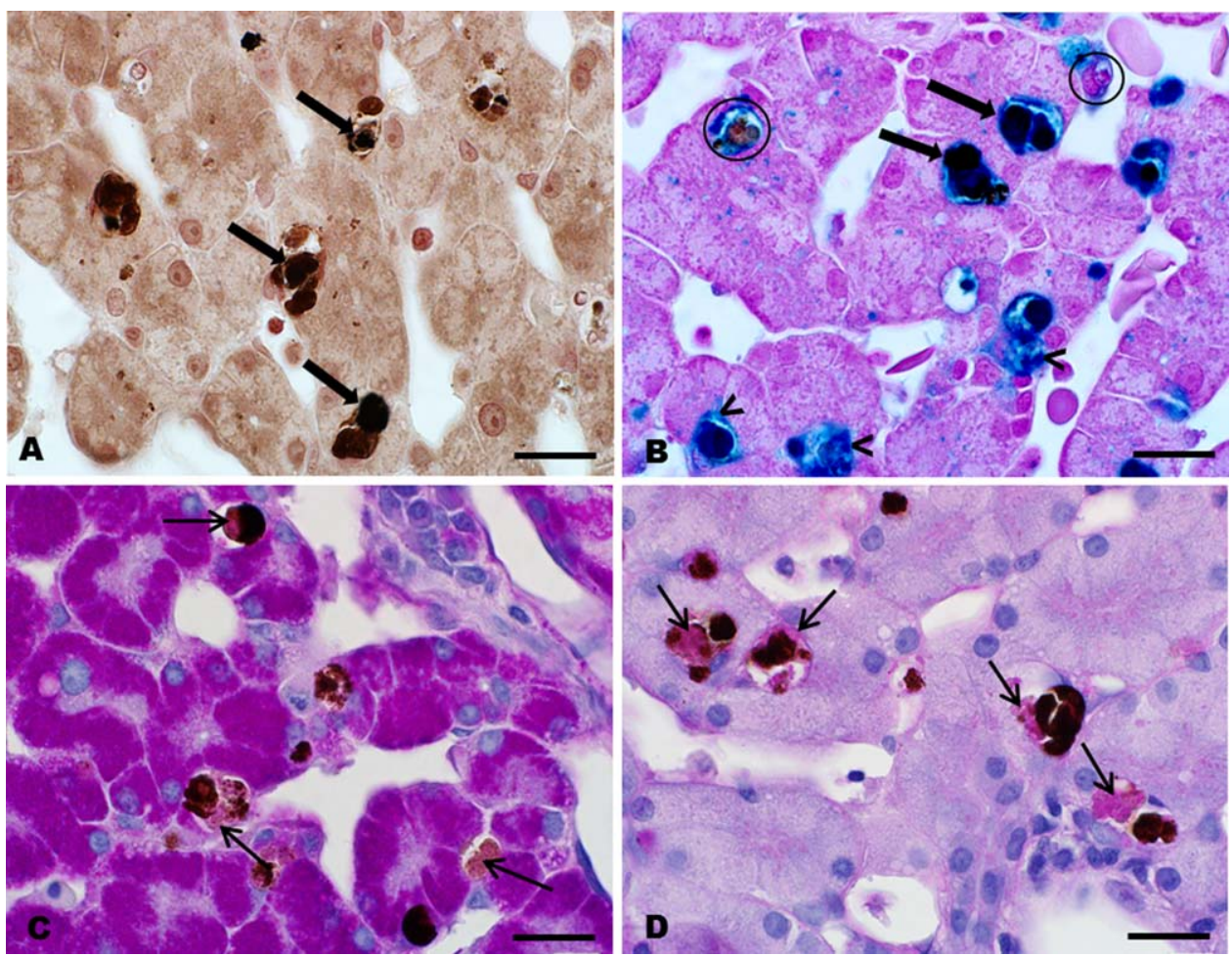

Fig. 1. C. niloticus, light micrographs of Kupffer cells in different locations in liver sections displaying compound phagosomes in the cytoplasm. (A) Masson-Fontana method showing positive black staining for melanin (arrows). (B) Blue positivity in phagosomes indicating the presence of hemosiderin (arrowheads) with the Perls' Prussian blue method. The presence of ceroid (pink component, encircled) and melanin (black component, arrows) is also indicated. (C, D) PAS and PAS-D staining revealing ceroid pigment (pink, arrows) in addition to the melanin (black) and hemosiderin (brown) contents. Bars $=20 \mu \mathrm{m}$.

the liver perfused for approximately 20 min until a pale discoloration of the tissue indicated successful perfusion. With the completion of the perfusion procedure tissue blocks were dissected from different areas in each of the five right liver lobes. The requirements of the Animal Use and Care Committee of the University of Pretoria were adhered to-protocol reference V040/05 and V041/05.

\section{Light Microscopy}

Tissue samples were placed in $10 \%$ aqueous buffered formalin ( $\mathrm{pH} 7.4,290 \mathrm{mOsm}$ ) and fixed for a minimum of $24 \mathrm{~h}$ before dehydrating through a graded ethanol series, clearing in xylene and infiltrating with paraffin wax in a Shandon Excelsior Tissue Processor (Labotec, South Africa). The samples were then embedded using a Shandon Thermolyne Histo Center II Embedding Unit (Labotec, South Africa) and 3-5 micron sections were cut with a Reichert-Jung rotary microtome (Premier Technologies, South Africa). Stains that were performed to illustrate Kupffer cells and their constituents included haematoxylin and eosin (H/E), toluidine blue (TB), Periodic Acid-Schiff (PAS) reaction, Periodic AcidSchiff reaction with diastase (PAS-D) treatment, Perls' Prussian blue reaction and Masson-Fontana (Bancroft, 1977). Slides of optimally perfused areas were examined by bright field illumination with an Olympus BX63 compound microscope (Olympus Corporation, Tokyo, Japan) and images digitally recorded. The cellSens Dimension software, version 1.5 (Olympus Corporation, Tokyo, Japan), was used to adjust the brightness and contrast of the images, and a sharpening filter was applied where needed.

\section{Transmission Electron Microscopy}

Small samples taken in parallel with the histology tissue blocks were dissected into $1 \mathrm{~mm}^{3}$ tissue blocks and immersed in 2.5\% glutaraldehyde in Millonig's phosphate buffer ( $\mathrm{pH} 7.2$, $0.13 \mathrm{M}$ ) for at least $24 \mathrm{~h}$. The tissue blocks were then rinsed in Millonig's buffer, postfixed in $1 \%$ osmium tetroxide in the same buffer for a minimum of $1 \mathrm{~h}$, rinsed again in buffer and dehydrated through a series of graded ethanol before infiltrating with propylene oxide and epoxy resin (TAAB 812 resin, TAAB Laboratories, England). TB-stained $0.35 \mu \mathrm{m}$ semithin resin sections were assessed light microscopically for the selection of optimally perfused areas (sinusoids not disrupted or collapsed) for ultrastructural examination. Ultrathin (50-90 nm) sections were cut on a Reichert-Jung Ultracut (C. Reichart AG., Vienna, Austria) using a diamond knife, collected onto copper grids and stained with Reynold's lead citrate and an aqueous saturated solution of uranyl acetate (Hayat, 2000). The ultrastructure of the Kupffer cells was examined with a Philips CM 10 transmission electron microscope (Philips Electron Optical Division, Eindhoven, The Netherlands) operated at $80 \mathrm{kV}$. A Megaview III side-mounted digital camera (Olympus Soft Imaging Solutions GmbH, Münster, Germany) was used to capture the images and iTEM software (Olympus Soft Imaging Solutions GmbH, Münster, Germany) to adjust the brightness and contrast.

\section{RESULTS \\ Light Microscopy}

Kupffer cells containing prominent yellow to brown compound cytoplasmic phagosomes formed part of the lining of the sinusoids, protruded into the sinusoidal lumen and were also located in the hepatic parenchyma (Figs.1A-D). The contents of the phagosomes were positive for both melanin, 

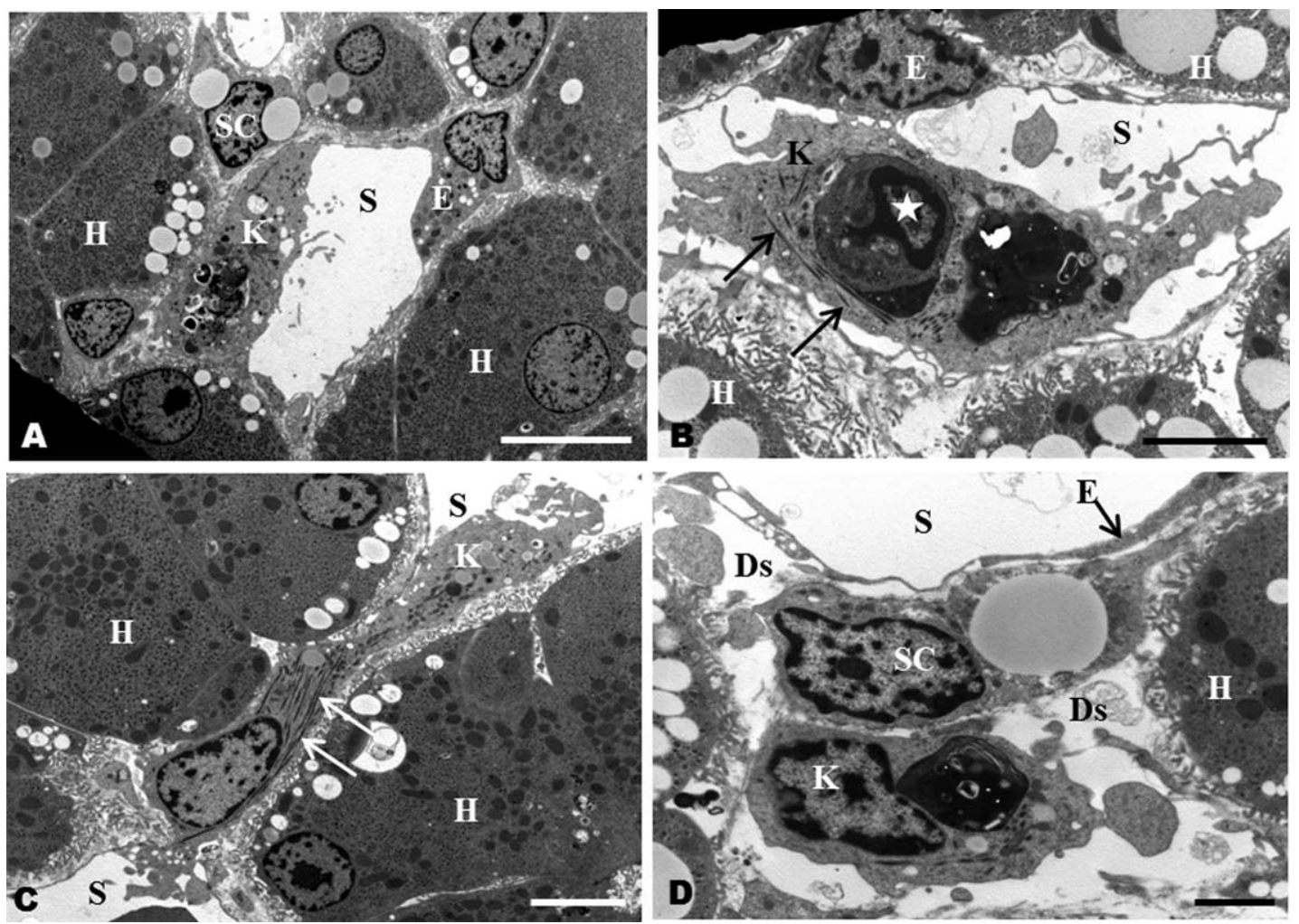

Fig. 2. C. niloticus, transmission electron micrographs illustrating the variable location of Kupffer cells. (A) A Kupffer cell forming part of the sinusoidal lining. (B) A Kupffer cell spanning the sinusoidal lumen. Note tubular structures (arrows) and phagocytosed cell (star). (C) A Kupffer cell inserted between groups of hepatocytes connecting adjacent sinusoids. Note tubular structures (arrows). (D) A Kupffer cell located in the space of Disse (Ds). E, endothelial cell; H, hepatocyte; K, Kupffer cell; S, sinusoid; SC, stellate cells with lipid droplets. Bars: (A) $10 \mu \mathrm{m}$; (B, C) $5 \mu \mathrm{m}$; (D) $2 \mu \mathrm{m}$.

with the Masson-Fontana method (Fig. 1A), and for hemosiderin, with the Perls' Prussian blue method (Fig. 1B). An additional pink-staining component, most likely ceroid pigment, was revealed in certain phagosomes with the PAS and PAS-D reaction (Fig. 1C, 1D). This component also retained a pink colour with the Perls' reaction (Fig. 1B).

\section{Transmission Electron Microscopy}

The Kupffer cells were large, pleomorphic pigmented cells that formed part of the sinusoidal lining (Fig. 2A), occasionally protruding into the sinusoidal lumen and sometimes spanning the lumen (Fig. 2B). They were often inserted between groups of hepatocytes forming bridges between adjacent sinusoids (Fig. 2C) and were also located in the space of Disse (Fig. 2D). Cells showing similar pigmentation were frequently noted as part of the hepatocyte cell cords (Fig. 3A). The Kupffer cells were not assembled in groups, but were seen as isolated cells in the areas mentioned. Their surfaces were irregular due to the presence of filopodia and lamelliapodia. No junctions were present between Kupffer and endothelial cells, but close contact and penetration through endothelial fenestrae (Fig. 3B) were seen in some instances. Kupffer cells were also seen interacting with pit cells.

Kupffer cell nuclei varied in shape (oval, elongated, round, angular) according to the cell's position, that is, elongated when the cell was extended between two adjacent sinusoids and more rounded when the cell was present in the sinusoidal lumen. The nuclei were often located eccentrically, exhibiting an indented angular shape, by conforming to the large compound phagosomes (Figs. 3A,D). Nuclear material sometimes appeared as clumps of heterochromatin throughout the nucleus and also formed a defined rim along the nuclear membrane. The nucleus was occasionally devoid of chromatin clumps with only an outer rim of heterochromatin surrounding a euchromatic interior being visible. Single nucleoli, occasionally consisting of a combination of electron-dense and pale components, were generally present.

Phagocytosis of apoptotic or dying white blood cells, red blood cells, thrombocytes and cellular debris was evident (Figs. 2B, 3C). The large compound phagosomes contained three major components, namely, clusters of melanosomes admixed with siderosomes and ceroid pigment (Figs. 3D, 4D). The melanosomes were pleomorphic ranging 

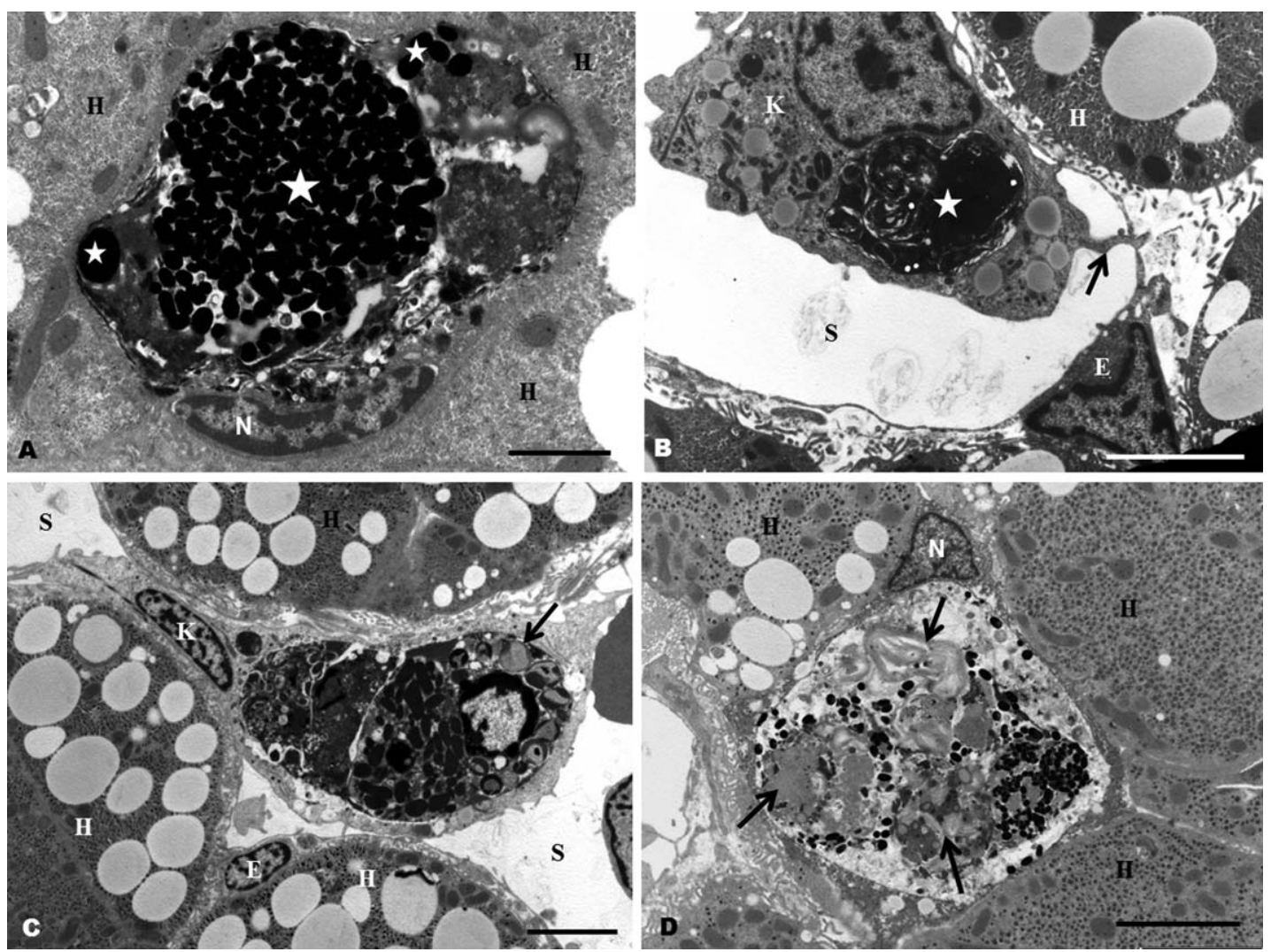

Fig. 3. (A) C. niloticus, a Kupffer cell forming part of a hepatocyte group. Note the eccentric nucleus (N) and compound phagosome containing melanin granules (stars) and cellular debris. (B) Penetration of a Kupffer cell filopodium (arrow) through an endothelial fenestra. Note lipid droplets and phagosome (star) in the cytoplasm. (C) A Kupffer cell containing a phagocytosed eosinophil (arrow). (D) A large phagosome showing distinct electron-dense melanin granules and ceroid pigment (arrows) of medium electron-density. Note the eccentric nucleus (N). E, endothelial cell; H, hepatocyte; K, Kupffer cell; S, sinusoid. Bars: (A) $2 \mu \mathrm{m}$; (B-D) $5 \mu \mathrm{m}$.

from elongate to oval to round, and also varied in size (Figs. 4A-D). Different developmental stages of the melanosomes were evident as expressed by the varied electron densities of the granule contents. Some melanosomes exhibited a filamentous interior while others were of medium electron density and contained electron-lucent spherical structures (about $25 \mathrm{~nm}$ in diameter, Fig. 4C). Yet others displayed a granular substructure, and several presented with varying electron densities with no obvious internal structure (Figs. 4B,C). Premelanosomes appeared as ill-defined, pale, membrane-bound structures (Fig. 4B). The melanosomes were not always contained within phagosomes, but also appeared free in the cytoplasm. The siderosomes enclosed numerous fine electrondense hemosiderin granules (Fig. 4D). Hemosiderin granules were also found lying free between the other constituents of the phagosomes. Ceroid pigment constituted the third component of the phagosomes and consisted of large nonmembrane bound, pleomorphic spherical structures of medium electron density (Figs. 3D, 4D). Myelinosomes and scanty lipid droplets were present among the cellular debris in some of the phagosomes.
Conspicuous cytoplasmic organelles that manifested as elongated, parallel tubular structures, some displaying a curved appearance, and bound by a single membrane were present. These structures were termed "tubulosomes." They were usually grouped together in longitudinal, transverse or oblique profile (Figs. 2B,C, 5A,B), but were also sometimes scattered in smaller groups around phagosomes. Depending on the plane of section the tubulosomes displayed electron-dense filamentous or crystalline material (Figs. 5C,D) with a clear zone present between this material and the limiting membrane. The cross-sectional profiles of the interiors varied, with circular, angular and divided contours being apparent (Figs. 5C-E). The width of the tubulosomes varied from 77 to 192 $\mathrm{nm}$ with the longest organelle observed measuring $6.5 \mu \mathrm{m}$. They were occasionally found in close association with mitochondria (Fig. 5F) from which they appeared to originate. The tubulosomes were also observed in the pigmented cells located between groups of hepatocytes.

Other constituents of the Kupffer cells included cytoplasmic lipid droplets, coated pits, microtubules, filaments, lysosomes, Golgi fields and granular and smooth endoplasmic reticulum. These 

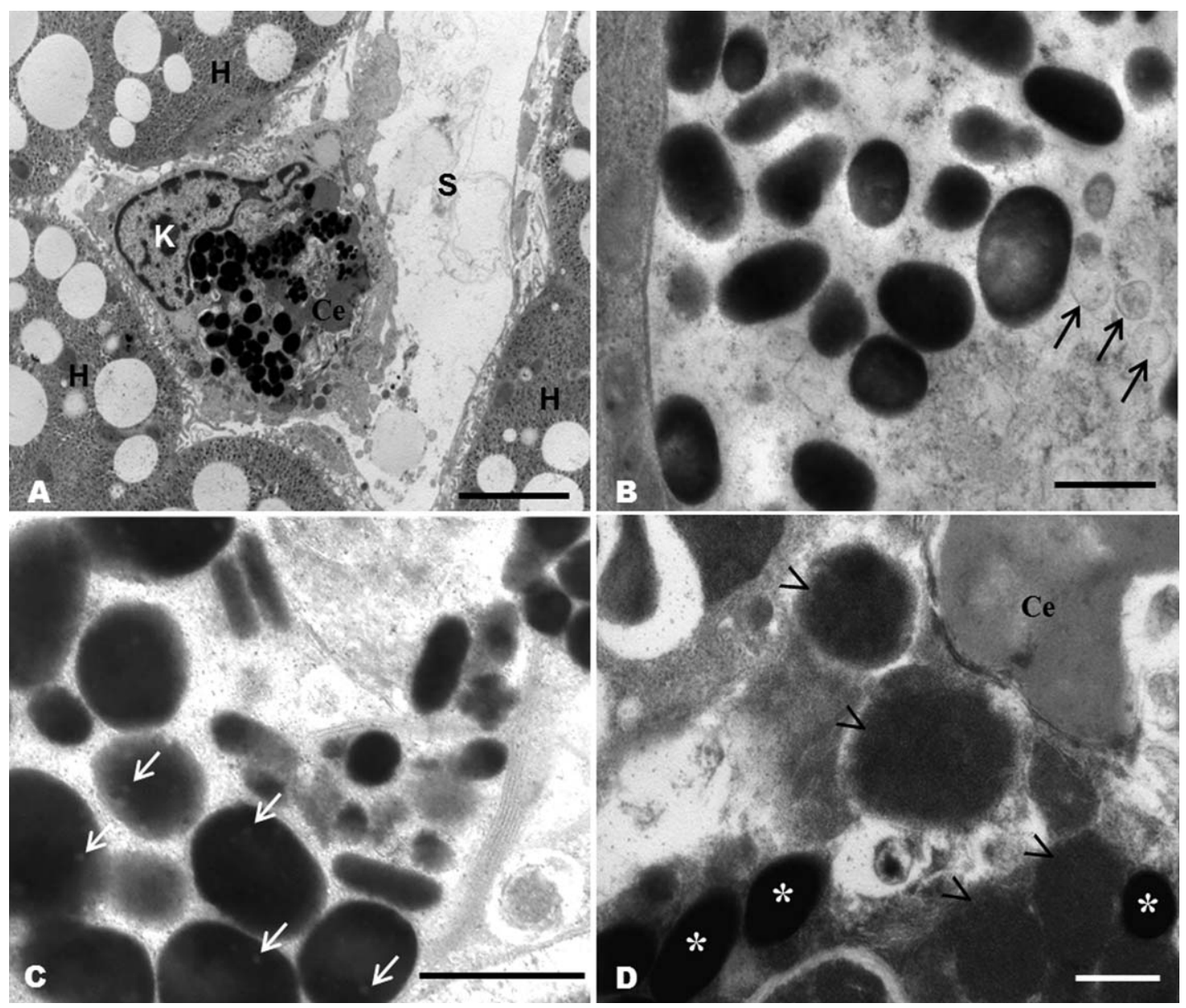

Fig. 4. C. niloticus, transmission electron micrographs illustrating the contents of phagosomes. (A) A Kupffer cell within the lumen of a sinusoid displaying pleomorphic melanosomes within a large compound phagosome. Note the ceroid pigment (Ce). (B) Melanosomes of varying electron densities. See the indistinct premelanosomes (arrows). (C) Melanosomes containing electron-lucent spherical structures (arrows). Note pleomorphism of the melanosomes. (D) Siderosomes (arrowheads), ceroid pigment (Ce) and electrondense melanosomes (asterisks). H, Hepatocyte; K, Kupffer cell; S, sinusoid. Bars: (A) 5 rm; (B-D) $500 \mathrm{~nm}$.

constituents showed no particular pattern of distribution.

\section{DISCUSSION \\ Light Microscopy}

The large yellow-brown cytoplasmic phagosomes seen in the Kupffer cells of the juvenile Nile crocodile were positive for both melanin and hemosiderin, a feature also described in other reptiles (Jacobson, 2007). Hemosiderin is usually seen in cells responsible for the breakdown of effete red blood cells and consists, among others, of ferritin and glycoproteins (Smith and Laurie, 2010). Ceroid pigment, lipofuscin pigment and glycoproteins are all PAS positive (Schaffner, 1998, Smith and Laurie, 2010) and may account for the third pink-staining element observed in the phagosomes. Ceroid and lipofuscin are both positive with the PAS-D reaction while glycoproteins are negative, excluding it as the third element. The rate of accumulation of ceroid and lipofuscin dif- fers, lipofuscin accumulates slowly with age, whereas the formation of ceroid pigment may occur rapidly at any age (Ghadially, 1988; Yin, 1996; Porta, 2002). We, therefore, suggest that the third element consists of ceroid pigment as the livers studied were obtained from juvenile crocodiles. Ceroid pigment occurs as residual bodies due to lysosomal activity (Ghadially, 1988) and represents degraded cellular debris (Schaffner, 1998). Ceroid is also described as a type of lipofuscin (Smith and Laurie, 2010), closely related to lipofuscin or even consisting of the same material in different oxidative stages (Ghadially, 1988).

\section{Transmission Electron Microscopy}

The location and positioning of Kupffer cells has been noted in several publications (Junqueira et al., 1975; Wisse and Knook, 1977; Phillips et al., 1987; Wisse et al., 1996; Ross et al., 2003; Ghoddusi and Kelly, 2004) including being found inside the sinusoidal lumen, forming part of the 

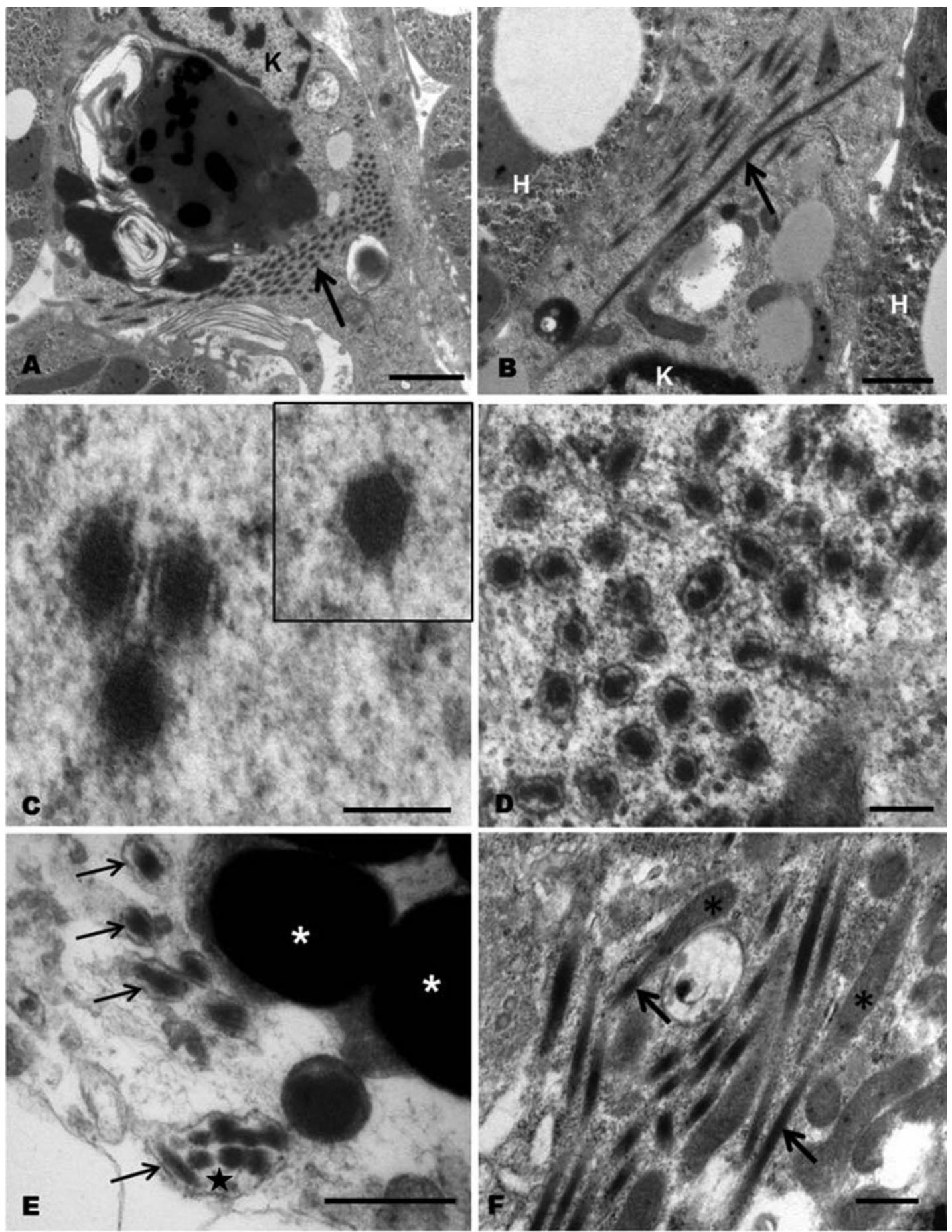

Fig. 5. C. niloticus, transmission electron micrographs of tubulosomes. (A) A group of tubulosomes in oblique section near a phagosome. (B) Tubulosomes sectioned in longitudinal profile (arrow). (C) Tubulosomes in oblique section displaying filamentous contents. (D) A group of tubulosomes in transverse section demonstrating crystalline contents. Note the variable interior profiles and the exterior clear zone. (E) A small group of tubulosomes (arrows) positioned near a collection of melanin granules (asterisks). Note the tubulosome containing a number of interior profiles (star). The clear zone around the cores of the organelles is again apparent. (F) Tubulosomes (arrows) in close association with mitochondria (asterisks). H, Hepatocyte; K, Kupffer cell. Bars: (A) $2 \mu \mathrm{m}$; (B) $1 \mu \mathrm{m}$; (C, D) $200 \mathrm{~nm}$; (E, F) $500 \mathrm{~nm}$.

sinusoidal lining, embedded in the endothelial lining, located as intraluminal macrophages or existing as fixed cells. Elias (1955) mentioned that the sinusoids of vertebrates were lined by potential phagocytes that never bridge the lumen and Naito et al. (2004) described Kupffer cells in mammals 
as being attached to the surfaces of fenestrated sinusoidal endothelial cells. In reptilian sauropsids, the Kupffer cells were attached to the endothelial surfaces of the sinusoids (Schaffner, 1998). They were present in the sinusoidal lumen and in the space of Disse of the West African crocodile (Storch et al., 1989). The Kupffer cells of the juvenile Nile crocodile liver did not reflect these findings as they were found in several positions, not only in the sinusoidal spaces but also bridging the sinusoidal lumen regularly, as well as occupying perisinusoidal locations. In the Nile crocodile, these cells can, therefore, be regarded as being highly mobile and not fixed cells.

Some authors differentiate between Kupffer cells and melanomacrophages which have also been referred to as "pigment cells" or "specialized Kupffer cells" when they contain melanosomes (Storch et al., 1989; Schaffner, 1998; McClellanGreen et al., 2006; Jacobson, 2007). The juvenile Nile crocodile liver contained numerous but isolated pigmented Kupffer cells as opposed to the collections of specialized Kupffer cells and pigment cells that had been noted in other reptiles (Hack and Helmy, 1964; Henninger, 1982; Henninger and Beresford, 1990; McClellan-Green et al., 2006; Jacobson, 2007). Storch (1989) distinguished between Kupffer cells and pigment cells in the West African crocodile describing them as two separate cell populations. Schaffner (1998) mentioned a second pigmented macrophage in addition to Kupffer cells in a perisinusoidal location in reptiles and Jacobson (2007) termed similar cells melanomacrophages. The present study identified matching ultrastructural features, including the tubular structures (tubulosomes), in the "pigmented" cells in all the mentioned locations, that is, sinusoidal, perisinusoidal and among hepatocytes, and concluded that these cells are all Kupffer cells. This concurs with findings in amphibians that the pigment cells in livers are Kupffer cells (Sichel et al., 1997).

The phagocytosis of apoptotic cells by Kupffer cells forms part of the regulatory processes of inflammation and immunity (Dini et al., 2002). Two pigments, namely melanin and hemosiderin, coexisted in the phagosomes of the Kupffer cells of the Nile crocodile. Hemosiderin is derived from the breakdown of haemoglobin and catalyses the formation of free superoxide radicals that are trapped by melanin (Beresford, 1987; Sichel et al., 2002; McClellan-Green et al., 2006). Kupffer cells of reptiles and amphibians are able to synthesize melanin (Henninger and Beresford, 1990; Kalashnikova 1992; Corsaro et al., 2000; Sichel et al., 2002) which is deposited in melanosomes. Melanosomes are specialised lysosomes (Orlow, 1995) and the production of melanin acts as a defence mechanism and as protection in response to the possibly harmful hemosiderin (Scalia et al., 1988, 1990;
Henninger and Beresford, 1990). The phagocytic process in the Kupffer cells of the Nile crocodile is consequently similar to that taking place in other reptiles and amphibians. The ultrastructural morphology of lipofuscin differs from that of the ceroid pigment present in the phagosomes of the Kupffer cells of the Nile crocodile. Lipofuscin consists of membrane-bound structures containing lipid droplets intermingled with electron-dense material (Ghadially, 1988), whereas the ceroid in the current study consisted of nonmembrane bound, pleomorphic spherical structures of medium electron density without the characteristic lipid droplets. This finding concurs with the light microscopical conclusion that the third element present in the phagosomes is ceroid pigment. Myelinosomes are additionally found in cells that have phagocytosed erythrocytes (Ghadially, 1988).

No structures comparable to the conspicuous tubular cytoplasmic organelles (tubulosomes) with filamentous or crystalline interiors found in the Kupffer cells could be traced in the literature. Storch et al. 1989 mentioned the presence of small membrane-bound vesicles of unknown origin in the Kupffer cells of the West African crocodile, however, no images were published to illustrate their structure. Boler (1969) described the ultrastructure of cytosomes in canine Kupffer cells, but these were larger than the tubulosomes, spherical in form and contained tubular structures. It is hypothesised that these organelles (tubulosomes), given their close relationship with the phagosomes, are specialised lysosomes involved in melanin synthesis and dedicated to the breakdown of phagosomal contents. Mitochondria are often closely associated with other organelles that require adenosine triphosphate (Lehninger, 1965, in Ghadially, 1988) for energy transfer, which may explain the close relationship between the tubulosomes and the mitochondria in the Kupffer cell cytoplasm of the Nile crocodile.

Lipid droplets were present in the Kupffer cells in this study, as well as in Kupffer cells of the lizard (Taira and Mutoh, 1981), but were absent in mammalian studies (McCuskey and McCuskey, 1990). Several of the mentioned publications refer to vermiform processes (invaginations of the cell membrane) formed by Kupffer cell membranes in mammals, but none were found in the liver of the juvenile Nile crocodile.

\section{ACKNOWLEDGMENTS}

The authors are grateful to Izintaba crocodile farm for donating the juvenile crocodiles, Ms. H. Rossouw (Physiology Section) for her expertise in perfusing the livers, Dr. J. Myburgh (Toxicology Section) for euthanizing the crocodiles, the Pathology Section for preparing the material for light microscopy and Prof JT Soley (Department of 
Anatomy \& Physiology) for critical appraisal of the manuscript.

\section{LITERATURE CITED}

Bancroft JD. 1977. Theory and Practice of Histological Techniques. London: Churchill Livingstone. $436 \mathrm{p}$.

Beresford WA. 1987. Some light microscopic histology of the liver in Caiman crocodilus. Anat Rec 218:16A.

Boler RK. 1969. Fine structure of canine Kupffer cells and their microtubule-containing cytosomes. Anat Rec 164:483-496.

Corsaro C, Scalia M, Leotta N, Mondio F, Sichel G. 2000. Characterisation of Kupffer cells in some Amphibia. J Anat 196: 249-261.

Dini L, Pagliara P, Carla EC. 2002. Phagocytosis of apoptotic cells by liver: A morphological study. Microsc Res Tech 57: $530-540$.

Elias H. 1955. Liver morphology. Biol Rev 30:263-310.

Fried GH. 2008. Liver. In AccessScience. (c) McGraw-Hill Education. Available at http://www.accessscience.com.

Ghadially FN. 1988. Ultrastructural Pathology of the Cell and Matrix. London: Butterworths. 1340 p.

Ghoddusi M, Kelly WR. 2004. Ultrastructure of in situ perfusion-fixed avian liver, with special reference to structure of the sinusoids. Microsc Res Tech 65:101-111.

Hack MH, Helmy FM. 1964. A comparative chemical study of the liver of various vertebrates. Acta Histochem 19:316-328.

Hayat MA. 2000. Principles and Techniques of Electron Microscopy: Biological Applications. London: Cambridge University Press. 543 p.

Henninger JM. 1982. Histology of the liver in the box turtle. Anat Rec 202:79A.

Henninger JM, Beresford WA. 1990. Is it coincidence that iron and melanin coexist in hepatic and other melanomacrophages? Histol Histopathol 5:457-459.

Jacobson ER. 2007. Overview of reptile biology, anatomy, and histology. In: Jacobson ER, editor. Infectious Diseases and Pathology of Reptiles. Florida: CRC Press. pp 1-130.

Junqueira LC, Carneiro J, Contopoulus AN. 1975. Basic Histology. California: Lange Medical Publications. $453 \mathrm{p}$.

Kalashnikova MM. 1992. Erythrophagocytosis and pigmented cells of the amphibian liver. Byulleten' Éksperimental'noi Biologii i Meditsiny 113:82-84.

McClellan-Green P, Celander M, Oberdörster E. 2006. Hepatic, renal, and adrenal toxicology. In: Gardner SC, Oberdörster E, editors. Toxicology of Reptiles. Florida: CRC Press. pp 123148.
McCuskey RS, McCuskey PA. 1990. Fine structure and function of Kupffer cells. J Electron Microsc Tech 14:237-246.

Naito M, Hasegawa G, Ebe Y, Yamamoto T. 2004. Differentiation and function of Kupffer cells. Med Electron Microsc 37: $16-28$.

Orlow SJ. 1995. Melanosomes are specialized members of the lysosomal lineage of organelles. J Invest Dermatol 105:3-7.

Phillips MJ, Poucell S, Patterson J, Valencia P. 1987. The normal liver. In: Phillips MJ, Poucell S, Patterson J, Valencia P, editors. The Liver: An Atlas and Text of Ultrastructural Pathology. New York: Raven Press. pp 1-11.

Porta EA. 2002. Pigments in aging: an overview. Ann N Y Acad Sci 959:57-65.

Ross MH, Kay GI, Pawlina W. 2003. Histology: A Text and Atlas. Baltimore: Lippincott Williams \& Wilkens. 875 p.

Scalia M, Geremia E, Corsaro C, Santoro S, Sciuto S, Sichel G. 1988. The extracutaneous pigmentary system: Evidence for the melanosynthesis in amphibia and reptilia liver. Comp Biochem Physiol 89B:715-717.

Scalia M, Geremia E, Corsaro C, Santoro C, Baratta D, Sichel G. 1990. Lipid peroxidation in pigmented and unpigmented liver tissues: Protective role of melanin. Pigment Cell Res 3: $115-119$.

Schaffner F. 1998. The liver. In: Gans C, editor. Biology of Reptilia, Vol. 19, (Morphology G: Visceral Organs). Missouri: Society for the Study of Amphibians and Reptiles. pp 485-531.

Sichel G, Scalia M, Mondio F, Corsaro C. 1997. The amphibian Kupffer cells build and demolish melanosomes: An ultrastructural point of view. Pigment Cell Res 10:271-287.

Sichel G, Scalia M, Corsaro C. 2002. Amphibia Kupffer cells. Microsc Res Tech 57:477-490.

Smith S, Laurie JH. 2010. Pigments and minerals. In: Kumar GL, Kiernan JA, editors. Education Guide: Special Stains and H \& E. California: Dako. pp 55-66.

Storch V, Braunbeck T, Waitkuwait WE. 1989. The liver of the West African crocodile Osteolaemus tetraspis. An ultrastructural study. J Submicrosc Cytol Pathol 21:317-327.

Taira K, Mutoh H. 1981. Comparative ultrastructural study of the Ito cells in the liver of some reptiles. Arch Histol Jpn 44: 373-384.

Wisse E, Knook DL. 1977. Kupffer Cells and Other Liver Sinusoidal Cells. Amsterdam: Elsevier. 537 p.

Wisse E, Braet F, Luo D, De Zanger R, Jans D, Crabbé E, Vermoesen A. 1996. Structure and function of sinusoidal lining cells in the liver. Toxicol Pathol 24:100-111.

Yin D. 1996. Biochemical basis of lipofuscin, ceroid, and age pigment-like fluorophores. Free Radic Biol Med 21:871-888. 